INDEPENDENT JOURNAL OF MANAGEMENT \& PRODUCTION (IJM\&P)

http://www.ijmp.jor.br

v. 11, n. 4, July - August 2020

ISSN: 2236-269X

DOI: 10.14807/ijmp.v11i4.1111

\title{
A HYBRID MODEL FOR PLANNING PROGRAMMING AND CONTROL OF PRODUCTION FOR MICRO AND SMALL ENTERPRISES
}

\author{
Evellyn de Morais Galvão \\ State University of Maringá - Production Engineering Department, \\ Brazil \\ E-mail: evelyn.mgalvao@gmail.com
}

Bianca Carina Valente State University of Maringá - Production Engineering Department, Brazil E-mail: biancacvalente1995@gmail.com

Syntia Lemos Cotrim State University of Maringá - Textile Engineering Department, Brazil E-mail: slcotrim2@uem.br

Gislaine Camila Lapasini Leal State University of Maringá - Production Engineering Department, Brazil E-mail:gclleal@uem.br

Edwin Vladimir Cardoza Galdamez State University of Maringá - Production Engineering Department, Brazil E-mail: evcgaldamez@uem.br

Submission: 8/8/2019 Revision: 9/18/2019 Accept: 10/2/2019

\section{ABSTRACT}

Competition among small and medium-sized enterprises has grown over the years due to the advancement of technology and the globalization of the market and operations. Production Planning, Programming and Control (PPCP) acts as a link between management and manufacturing, in these small and medium-sized enterprises. The present study, through an action research in a microenterprise manufacturer of Brooms made of PET, aimed at the implementation of a hybrid PPCP system. The model was proposed by using the concepts of Lean Manufacturing, to map and know the process eliminating wasted time and resources, Theory of Constraints to identify constraints and bottlenecks and the MRP system to act within the context of pushed 
DOI: 10.14807/ijmp.v11i4.1111

production. Therefore, it is possible to obtain a Framework that presents the method used in the implementation of the work, which provided with results such as production order, security stock, and correct input definition. The model put the company in other level of organization and efficiency in the use of resources.

Keywords: Hybrid PPCP system; Lean Manufacturing; Theory of Constraints; MRP system.

\section{INTRODUCTION}

With the increasing volume of small and medium-sized enterprises, their importance has also grown for the economic sectors of the countries, with these large jobs generators and, therefore Beck and Kunt (2006) points out that small and medium enterprises form a large part of private sector in many developed and developing countries.

As observed by Giaoutzi, Nijkamp and Storey (2016) widely believed that micro and small enterprises contain the rejuvenation potential that is necessary for revitalizing the industrial and service sector in our stagnating economies, and in this context, they are consequently also often regarded as the vehicles for regional development planning (GIAOUTZI et al., 2016).

According to Fosman and Rantanen (2011) “... small enterprises are considered to be more innovative due to their flexibility, higher ability to adapt and improve, and because they are quick movers in implementing change.” Additionally, Acs, Morck, Shaver and Yeung (1997) points out that the modern economy, innovation remains largely the work of smaller firms.

Gunasekaran, Rai and Griffin (2011) points out that competition among small and medium-sized enterprises has grown over the years due to the advancement of technology and the globalization of the market and operations, so their survival depends on their resilience to guide their strategies and technologies.

Planning, Programming and Control of Production has been one of the primary publishing outlets for operations management research for nearly three decades, according to Akmal, Podgorodnichenko, Greatbanks and Everett (2018).

That concept has become increasingly important for the companies because it manages the flow of materials from the production system through the flow of information and decisions, corroborating the information of Fernandes, Azeka, Barreto and Filho (2007). It means the 
DOI: 10.14807/ijmp.v11i4.1111

resources need to be available in the appropriate quantity, at the appropriate time, and the appropriate quality level (FERNANDES et al., 2007).

It is in this context that the Planning, Programming and Control of Production emerges as an essential tool to achieve the survival and maintenance of micro and small enterprises in the competitive market.

Among the small and medium-sized companies in Brazil, one segment that has been showing notable growth is the recycled PET segment. According to the Business Compromise Recycling Association (CEMPRE, 2018) 59\% of PET packaging was recycled in 2012, totaling 331 thousand tons. The 10th edition of the PET Recycling Census in Brazil by the Brazilian PET Industry Association showed that in 2016, 34\% of PET bales dedicated to recycling were obtained through collectors (ABIPET, 2016).

Therefore, this article aims to propose a hybrid model to planning, programming and control of production for micro and small enterprises with integration of tools such as planning programming and control of production, along with Lean Manufacturing, Theory of Constraints (TOC) and Material Requirement Planning (MRP). The model will be evaluated through an application study in a small ecological broom factory in the city of Maringá, Brazil. An Application Study presents an example of application in the industrial context and serves as proof of a concept. In this case, the study was conducted in a single company and in a specific project, given the required time and involvement required of the entrepreneurs.

\section{LITERATURE REVIEW}

\subsection{PPCP for Micro and Small Enterprises}

According to Kuazaqui (2013), Micro and Small Companies have an important socioeconomic role in Brazil and in the world; they are still responsible for the generation of new ideas, products, services and operations, since they usually result from a more entrepreneurial vision with possibilities to use creativity and innovation more quickly and freely.

Among the difficulties and limitations faced by Micro and Small Companies, Galdámez (2007) points out that factors such as competition, competitiveness of large companies and constant technological changes in both products and production processes end up being decisive for their performance. 
DOI: 10.14807/ijmp.v11i4.1111

Therefore, the production management becomes a key role for this type of enterprise, because as reported by Assid, Gharb and Dhouib (2015), Wang and Liu (2013) and Fernandes, Filho and Bonney (2009) manufacturing systems require control and monitoring, especially in a constantly changing and increasingly complex economic environment, meeting the quality, time and cost objectives.

\subsection{Hybrid Model for Planning, Programming and Control of Production (PPCP)}

Bertolini, Romagnoli and Zammori (2015) point out that PPCP systems have been the subject of research on operations management in the last 30 years. Within this objective of planning and controlling production are the hybrid systems of PPCP, which are called hybrid functions, that is, because they operate with both, pulled and pushed production.

Authors such as Korugan and Gupta (2014) and Guan, Ma and Yin (2015) point out that in hybrid production systems one of the challenges lies in the search for a balance in the stock between processes. It is also related to the good levels of finished product stocks, as well as quantity, quality and time.

Korugan and Gupta (2014) also point out that in a hybrid model of production process there is always the question of the uncertainty and high variability that can occur at the ends of the process. Therefore, it is necessary that the control mechanisms for these systems be adapted to these characteristics.

\section{RESEARCH METHODOLOGY}

Research can be defined as a scientific and systematic on a specific topic from relevant information; in common, parlance refers to a search for knowledge or an art of scientific investigation (KOTHARI, 2004).

The research study can be classified from the viewpoint of: application, perspectives of objectives and enquiry mode employed (KUMAR, 2011). From the viewpoint of enquiry model employed this study is qualitative and quantitative. When the research is based on the measurement of quantity or amount it is considered quantitative (KOTHARI, 2004). Qualitative research, on the other hand, has the purpose to describe a situation, phenomenon, problem or event with the information gathered through the use of variables measured on nominal or ordinal scales (KUMAR, 2011).

From the viewpoint of objectives, the research is an Application Study, allowing to evaluate the methods and tools under the business approach (SJOBERG; DYBA; 
DOI: 10.14807/ijmp.v11i4.1111

JORGENSEN, 2007). In addition, there are a variety of data sources (interviews, observation, qualitative data) and the unit of analysis can be a company, a project, a team, a team member, a special event or a specific work product (EASTERBROOK, et al., 2008). In this case, the study was conducted in a single company and in a specific project, given the required time and involvement required of the entrepreneurs.

\subsection{Proposed Model}

Small and medium-sized businesses often have difficulty working with a pull production system; a fact that contributes to this is that there is not enough demand, so Just in Time must involve negotiations with suppliers to make this model possible. In addition to this fact, the high turnover rate causes difficulties to maintain training, culture and discipline among the staff, factors that are essential to a pulled system.

In this way, the proposed framework seeks to follow the principle that a hybrid model of PPCP for small and medium-sized enterprises should be able to operate with pulled production, to wipe and schedule production, to reduce stock levels and identify their bottlenecks.

The Framework of this study, which proposes a generic hybrid model of PPCP, is represented in Figure 1.

The Framework is divided into three stages: Planning, Programming and Control of Production, and in each of them the concepts that support the accomplishment of this work, are: Lean Manufacturing, Theory of Constraints (TOC) and Material Requirement Planning (MRP).

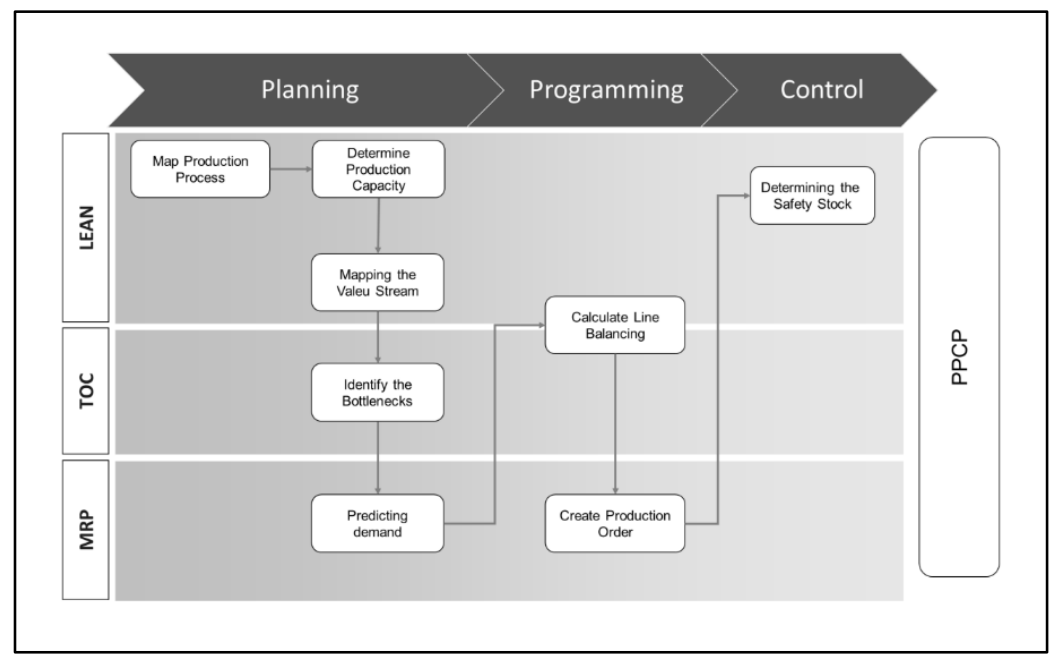

Figure 1: Framework: Hybrid model to planning programming and control of production for micro and small enterprises 
DOI: 10.14807/ijmp.v11i4.1111

The concept of Lean Manufacturing gave the researcher and the company the knowledge of the productive process and its value chain in order to reduce everything that was surplus. The MRP system supported the verification of the demand for the company's products and production orders of them.

Finally, the TOC made it possible to identify production bottlenecks and other limitations of the system. Alves, Santos and Schmidt (2014) point out that there are two assumptions addressed in TOC: the first is to consider the company as a system whose success or failure depends on how different processes interact with each other and the second is that a restriction is any factor that limits the system to reach its goal.

The proposed framework is prescriptive; it presents recommendations that guide the execution of the activities, highlighting what should be done. The framework is structured in stages, which are composed of activities, which have a purpose and associated recommendations. Stages group activities according to a common goal. The activities have a purpose, which aims to determine what it should achieve. The recommendations aim to identify means to carry out the activity, and may take the form of guidance, practices and / or tools.

Then each activity within each of the three stages is detailed according to its steps of execution:

The Planning stage aims to understand the production process, its limits and predict the behavior of the demand of the products, is composed of the following activities: Map production process, determine production capacity, map the value stream, identify the bottlenecks and predicting demand.

Mapping the Productive Process aims to identify the activities that make up the productive process and its relations. To perform this activity, it is recommended to interview the employees, collect process data using the SIPOC, map the production process, validate the mapping with employees. It also uses concepts from the Business Process Modeling Notation (BPMn) methodology.

The Determine Production Capacity activity aims to identify the plant's capacity to produce its different products. It is recommended to use the concepts provided by Lean Manufacturing to support the calculations of productive capacity.

The Value Stream Mapping activity is intended to classify the types of processes that exist in the system. It is recommended to collect the description of the activities done by the employees. Then, observe the activity performed by the employee, collect information about 
DOI: 10.14807/ijmp.v11i4.1111

inventory and waste before and after the process, collect the times that add and do not add value in the process and finally elaborate the Value Stream Map with the help of Visio software, supported once again by the concepts of Lean Manufacturing.

The purpose of Identifying bottlenecks is to identify and list system constraints. It is recommended to develop the Value Stream Map and then, with its analysis, identify the existing bottleneck activities, using the principles provided by TOC.

The Predicting demand activity aims to identify seasonality and trends in order to estimate the demand for products. It is recommended to collect the sales data of the previous periods and to identify the seasonality and trends, to define the calculation method of demand forecast that best suits the case, to finally carry out the forecast of demand, based on the concept of MRP, which supports that the company should only produce the required quantity demanded.

The Programing stage aims to define the resources that will be used from the beginning to the end of the production flow, is composed of the following activities: Calculate line balancing and create production order.

The Calculate line balancing activity aims, with the help of the concepts of TOC and Lean Manufacturing, to analyze and establish the percentage relation of sales of the product groups. I also aim to analyze and establish the percentage relation of sales of the existing products in each group, establish the quantity to be produced of each product and to balance the production respecting the restrictions already identified.

The purpose of the Production Order activity is to produce the Production Order following the demands, as suggested by the MRP system.

The Control stage aims to ensure that the process is performed in the best possible way by operating with sufficient quantity of inputs and products to meet the needs of the plant, and is composed by the activity of determining Security stock.

The Determine Security Stock activity is intended to define the quantities of raw materials and / or finished products needed to meet the system's needs. It is recommended to use the concepts Just in Time addressed in the philosophy of Lean Manufacturing to work with the lowest security stock and thus reduce factory costs. Zahraei and Chee-Chon (2017) points security stocks is one of the most common tactics employed to mitigate variability and used to hedge against unexpected surges in demand. 
DOI: 10.14807/ijmp.v11i4.1111

The framework presents a systemic view regarding PPCP for micro and small enterprises, defines the activities that must be carried out and points out recommendations for their execution.

\section{RESULTS ANALYSIS}

The company under study works in the PET bottle recycling market for the production of domestic ecological brooms. Its products, are destined for both domestic and industrial use, being the industrial the largest selling point, since its differential is empirical proven to last up to 30 times more than the same product of the conventional line, fact that attracts industries that look for greater economy and sustainability in its businesses.

The company operates with a pushed production process, where the products are produced, stored and later have their output of stock as they are sold, which sometimes causes high volume of inventory, and others in unavailability of products for sale, due to the its randomness of production. The implementation of a hybrid model of PPCP would enable the company to better manage inputs, stocks and capital, making it a strategic survival factor in the competitive market.

This study starts from the point that an earlier study was carried out in the company, resulting in a Standardized Production Balancing (SPB), which gave employees a routine work and a daily production and sales target. As well as the framework already presented, this section will be divided into three main stages: Planning, Programming and Control of Production.

\subsection{Planning}

\subsubsection{Map Production Process and Determine Production Capacity}

The planning stage began with the on-site visits to the production area, which aimed to enable the researchers to know the production process, the activities of the operators and the resources needed for the process. During the visits, interviews were carried out with the operators, through a structured form, which sought to understand in detail how the production process occurred and the flow of activities of the production of domestic and industrial brooms.

Then, using the mapping technique in Brown Paper, an outline of the processes mapping was elaborated based on the information collected. The technique enabled an instant view of the process, since all involved participated and collaborated with ideas, drawing on a large sheet of paper all existing activities, as well as their inputs and outputs. The operators validated the map. 
DOI: 10.14807/ijmp.v11i4.1111

With the mapping of processes, it was possible to identify the productive capacity of the Domestic brooms, model 78 and 98 tuffs, and Industrial brooms, focus of this work. For this, the setup time and the cycle time of the operation, were calculated and the productive capacity per activity was calculated over a period of 1 hour. The values obtained are shown in Figure 2.

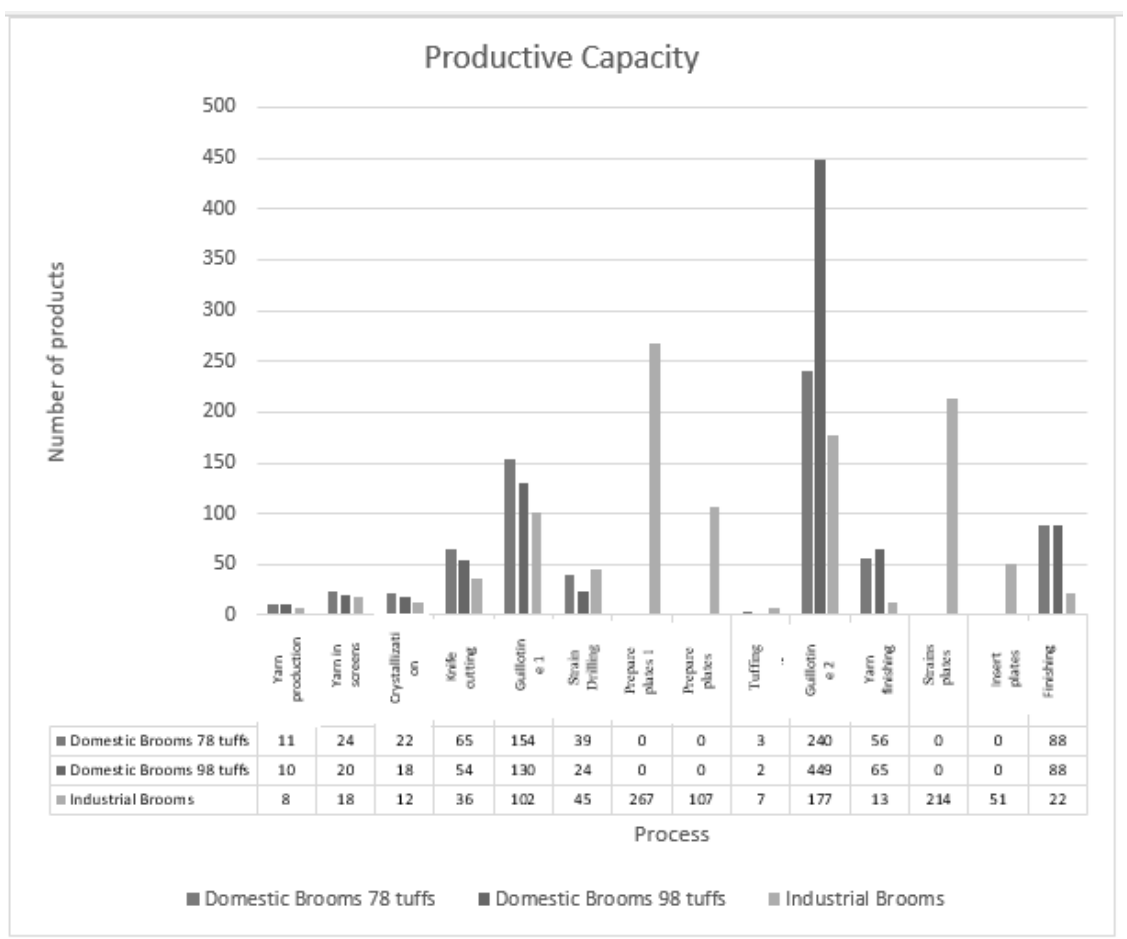

Figure 2: Productive Capacity of Domestic brooms and Industrial brooms

It can be observed in Figure 2 that the Cutting in Guillotine 2 activity is the one with the highest Productive Capacity due to its fast execution, while the Tufing process presents the lowest Productive Capacity, becoming the production bottleneck of the factory.

Once the process with the operators was validated and the productive capacity was calculated, Bizagi Modeler - Version 3.0.0.022 software was used to register the mapping of BPMn language processes.

\subsection{2. $\quad$ Mapping the Value Stream (VSM)}

For the construction of the Value Stream Map, it was first necessary to divide the products into groups according to the similarities in their processes. The groups defined were:

- Group A: Domestic brooms with 78 tuffs;

- Group B: Domestic brooms with 98 tuffs;

- Group C: Industrial brooms. 
DOI: 10.14807/ijmp.v11i4.1111

Then the existing processes in each product were classified in the following categories: i) abstract processes: outsourced processes; ii) private processes: those carried out by the company from start to finish; iii) collaborative processes: those that occur outside the company and part within the company.

Once the groups were defined and the processes were classified, the data was collected. Then, the researcher had to fill out a second form containing the information, such as the names of the persons responsible for collecting the data, the language used, the date, the name of the product being mapped, the name of the process the data would be collected, and the classification of its category. The collection started with the description of the activities by the operator while the researcher completed the form. After that, the operator simulated the activity and adjustments in the form were performed, when necessary.

With the form already completed, the quantities of products that would compose the production lots were defined, and then the time collection was started. For the collection, it was necessary for two researchers to perform the timing, being the first one responsible for timing the cycle time, that is, the total time of the process. And the second researcher was responsible for collecting the operation time, or activities that added value to the product, which means that every time the operator performs a task that does not add value the timer should be stopped. This activity was performed for 1 month. Thus, the the Cycle and Operation times were collected.

For the creation of the Value Stream Map, it was still necessary for the researchers to identify the inventories, identify the generated residues, and identify what the suppliers and customers of each stage of the process are. With all data, it was possible to construct the Value Stream Map, for each group of products.

Analyzing the Value Stream Map of Group A, one can observe the volume of input stock between the processes, with the highest levels being concentrated in three processes. Among the Weighing and Separation and Screen Fill processes, the volume of reels stored allowed the production of 969 products. In the strain Drilling process, the stock of available strains would allow the production of 449 domestic brooms. Already in the process of Tuffing it was possible to produce 432 products with tufts stocked.

The largest stock indices are among the same Group B processes; however, the volume capable of being produced differs due to different input requirements. In this group among the 
DOI: 10.14807/ijmp.v11i4.1111

processes of Weighing and Separation and Filling of Screens would be possible to produce 835 domestic brooms, in the Drilling of Strain, 391 and in the Tuffing 233 products.

For Group C, other processes such as those with higher volumes of stocks were Cutting on Guillotine 1 and Preparation of plates 1, with the possibility of producing 5240 and 1265 industrial brooms, respectively.

In addition, the Value Stream Map also made it possible to analyze the times of activities that aggregate and do not add value to the product. For Group A it was assumed that $44.73 \%$ of the production time adds value, that is, time that the customer is willing to pay to have the product he wants and the remaining $57.21 \%$ are times used for activities that do not add value, such as: wait, setup, movimentation, among others.

Group B presented $42.79 \%$ for activities that add value and $57.21 \%$ for those that do not aggregate. Finally, in Group C, $41.63 \%$ of the time is allocated to activities that aggregate and $58.37 \%$ to those that do not add value, as summarized in Figure 3.

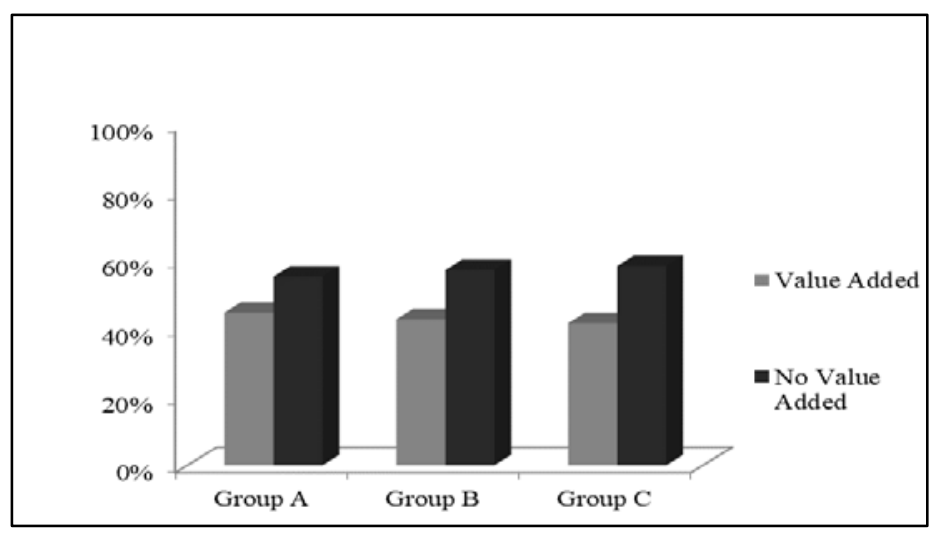

Figure 3: Process times that aggregate and do not add value to the process

\subsubsection{Identify the Bottlenecks (TOC)}

In this step, the concepts of the Constraint Theory were used to identify bottlenecks in the system. Firstly, it was identified, with the aid of the Value Stream Map, the bottleneck process in the production of each group of products.

For all three groups the same process was identified as bottleneck: Tuffing. The tuffing process makes the production of group A in 1 hour of work are 3 domestic brooms, group B of 2 domestic brooms and group $\mathrm{C}$ of 7 industrial brooms. Due to the low productive capacity of this process, it was decided not to adjust the other processes to this bottleneck, which would cause the production of the plant to suffer a considerable fall. 
DOI: 10.14807/ijmp.v11i4.1111

In addition to identifying production bottlenecks, it was sought to identify the limiting factors related to inputs, suppliers, labor, among others, since these also have an impact on productive efficiency. As other limiting factors were listed: i) specific day in the week to receive the outsourced products and raw material (brushes); ii) limited amount of screen size; (iii) the number of spools divided by color; iv) types of activities performed by employees; v) productive efficiency of approximately $80 \%$, to consider the worker's stops and fatigues.

Identifying the limiting factors and the bottlenecks of the productive process, the last step of the planning process was to predict demand.

\subsubsection{Predicting Demand}

This stage began with the analysis of sales from previous years. We chose to use as data the sales volumes of the last three, due to the fact that in the years prior to these sales were controlled manually and, therefore, the data do not have a great reliability and accuracy.

First, the data divided into two major product groups were analyzed: domestic brooms and industrial brooms in order to identify trends or seasonality's.

When analyzing the behavior in general, by means of the average sales of the three years, one perceives a more constant behavior when compared to the annual values, with absence of large ascending or descending.

In general, the analysis of the data allowed identifying the absence of seasonality's or trends in the behavior of the sales of the products over the years, although some peaks and gaps were noticed. In addition, since the data used were products sold over the months, one can restrict as a forecast calculation method those with an approach based on time series. Among the options with a time series approach, the most adequate would be the Average Moving Average, since we can determine the most recent $\mathrm{N}$ periods, making its behavior more assertive about the variations in demand.

For these calculations the equation proposed by Fernandes and Godinho Filho (2010) was used:

$$
X(t+1)=\frac{\sum_{1}^{N} X(t-N)}{N}
$$

Where:

- $\quad$ N: periods;

- $\quad \mathrm{t}$ : present time; 
DOI: 10.14807/ijmp.v11i4.1111

- $\mathrm{X}(\mathrm{t}+1)$ : future point;

- $\mathrm{X}(\mathrm{t}-\mathrm{N})$ : values of the previous periods used.

In order to carry out the demand forecast of the domestic brooms and industrial brooms groups, the average sales of each month were calculated based on the last three years, disregarding some values highlighted in gray, which could cause its characterization, resulting in a forecast farther from the reality.

Analyzing the data, it was possible to notice a lower average sale in the periods of December, January and February for the group of domestic brooms and a more constant behavior throughout the rest of the year.

With the monthly averages, it was possible to start the calculation of demand forecast for year 4 . The sales volumes of the last three months of year 3 were considered to calculate the demand forecast for January of year 4, according to the equation mentioned above.

\subsection{Programming}

After completing the planning stage, it was possible to start the programming stage, which was divided into two activities, the first the production balancing and the second the elaboration of the production orders.

\subsubsection{Calculate Line Balancing}

In this activity of balancing production, it was established the production and sales goals for each product of each group (domestic brooms and industrial brooms), using the sales data from previous years and the demand forecast elaborated in the planning stage. I was defined the need for the main input (brushes) and establish the balance of existing activities in the production process.

The balancing was based on the need to reduce inventories of finished products, products in process and inputs, in addition to aligning suppliers with the company's production activities. As a first step in balancing production, it was analyzed the sales percentages of the products divided into two groups: domestic brooms and industrial brooms, as shown in Figure 4. 
DOI: 10.14807/ijmp.v11i4.1111

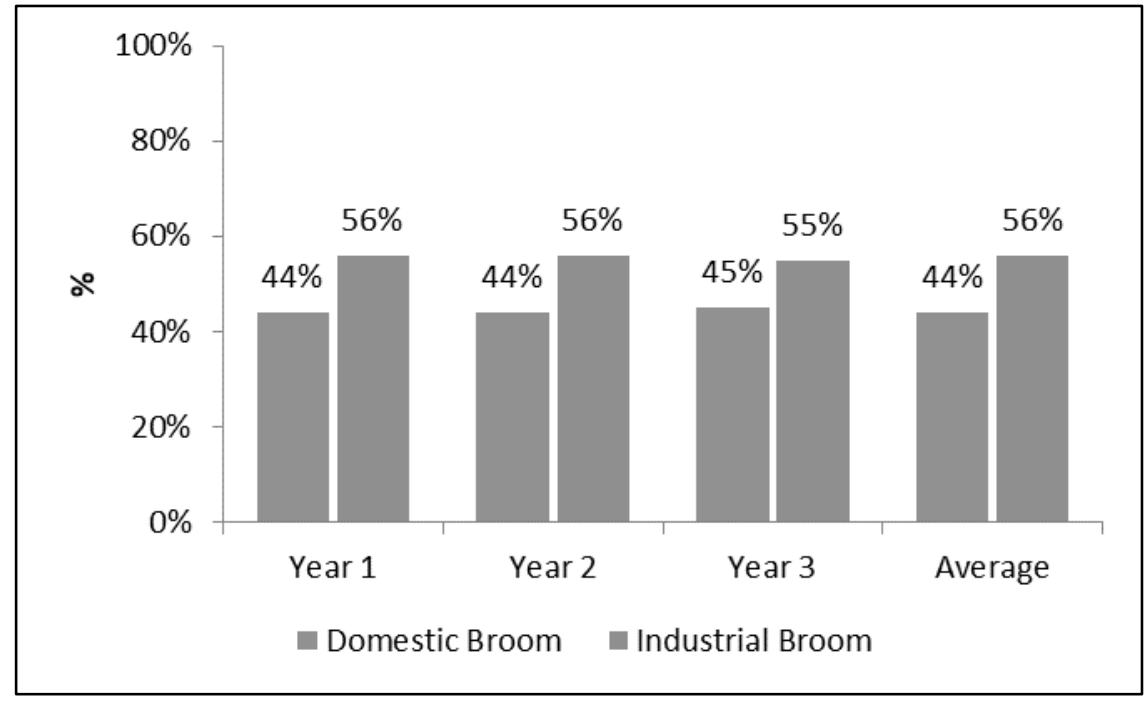

Figure 4: Ratio of Sales of Domestic and Industrial brooms

From Figure 4 it can be seen that the ratio of proportionality of sales between the two groups remained stable between the three years, which allowed establishing as a goal the ratio of $56 \%$ of production for industrial brooms and $44 \%$ for domestic brooms, of total volume of 1000 already established previously.

Once the production goal of the two groups was defined, sales for the year 1 were taken to adjust the proportion obtained to the established sales and production target of 1000 products. Tables 1 and 2 show the monthly output estimated by product considering the goals of 440 domestic brooms and 560 industrial brooms.

Table 1: Estimated monthly production of domestic brooms for year 4

\begin{tabular}{c|c|c|c}
\hline Product & Average & $\%$ & $\begin{array}{c}\text { Estimated } \\
\text { Production }\end{array}$ \\
\hline Domestic 1 & 115 & $31 \%$ & 135 \\
\hline Domestic 2 & 105 & $28 \%$ & 123 \\
\hline Domestic 3 & 71 & $19 \%$ & 82 \\
\hline Industrial & 64 & $17 \%$ & 75 \\
\hline Anatomic & 11 & $3 \%$ & 13 \\
\hline Industrial 2 & 10 & $3 \%$ & 13 \\
\hline Total & 376 & $100 \%$ & 440 \\
\hline
\end{tabular}

Table 1, adjusted for the total monthly output of 440 products of the domestic brooms group, brings as an estimated monthly output 135 Domestic 2 brooms and 123 Domestic 3, these being both the group's leading sellers.

Table 2: Estimated monthly production of industrial brooms for year 4

\begin{tabular}{c|c|c|c}
\hline Product & Average & $\%$ & $\begin{array}{c}\text { Estimated } \\
\text { Production }\end{array}$ \\
\hline Industrial brooms $40 \mathrm{~cm}$ & 409 & $89 \%$ & 500 \\
\hline
\end{tabular}


DOI: 10.14807/ijmp.v11i4.1111

\begin{tabular}{c|c|c|c} 
Industrial brooms $60 \mathrm{~cm}$ & 31 & $7 \%$ & 38 \\
\hline Industrial brooms short & 18 & $4 \%$ & 22 \\
\hline Total & 458 & $100 \%$ & 560 \\
\hline
\end{tabular}

Table 2, adjusted for the total monthly production of 560 products of the brooms industrial group, brings the estimated monthly production of three different products, being Industrial brooms $40 \mathrm{~cm}$ with $89 \%$ of the group's total sales, with an estimated production of 500 products per month.

Estimated the monthly production of each product for year 4, one can establish the monthly need for yarns for production. To calculate the required amount of yarn, the products were divided according to the type of yarn used (thick or thin) and then the amount per color (green or white) was calculated. The results are shown in Table 3.

Table 3: Monthly yarn requirement by type and color for each product

\begin{tabular}{c|c|c|c|c|c|c|c}
\hline Product & $\begin{array}{c}\text { Weekly } \\
\text { production } \\
\text { forecast }\end{array}$ & $\begin{array}{c}\text { Type of } \\
\text { yarn }\end{array}$ & $\begin{array}{c}\text { Yarn per } \\
\text { unit (Kg) }\end{array}$ & $\begin{array}{c}\text { Green } \\
\text { yarn per } \\
\text { unit (Kg) }\end{array}$ & $\begin{array}{c}\text { White } \\
\text { yarn per } \\
\text { unit (Kg) }\end{array}$ & $\begin{array}{c}\text { Total } \\
\text { Green } \\
\text { yarn (Kg) }\end{array}$ & $\begin{array}{c}\text { Total } \\
\text { White } \\
\text { yarn (Kg) }\end{array}$ \\
\hline Industrial 40cm & 125 & Thick & 0,353 & 0,353 & 0,000 & 44,125 & 0,000 \\
\hline Domestic 2 & 33,75 & Thin & 0,260 & 0,138 & 0,122 & 4,658 & 4,118 \\
\hline Domestic 3 & 30,75 & Thin & 0,207 & 0,111 & 0,096 & 3,413 & 2,952 \\
\hline Domestic 1 & 20,5 & Thick & 0,230 & 0,124 & 0,106 & 2,542 & 2,173 \\
\hline Industrial & 18,75 & Thick & 0,230 & 0,000 & 0,230 & 0,000 & 4,313 \\
\hline Industrial 60cm & 9,5 & Thick & 0,470 & 0,470 & 0,000 & 4,465 & 0,000 \\
\hline Industrial short & 5,5 & Thick & 0,335 & 0,335 & 0,000 & 1,843 & 0,000 \\
\hline Anatomic & 3,25 & Thin & 0,207 & 0,111 & 0,096 & 0,361 & 0,312 \\
\hline Industrial 2 & 3 & Thin & 0,400 & 0,218 & 0,182 & 0,654 & 0,546 \\
\hline
\end{tabular}

With the values of the required monthly quantity of each yarn for each product, one can calculate the total monthly quantity of each yarn, to reach the necessary monthly quantity of reels to supply the proposed production. Figure 5 shows the total amount of yarn divided by category.

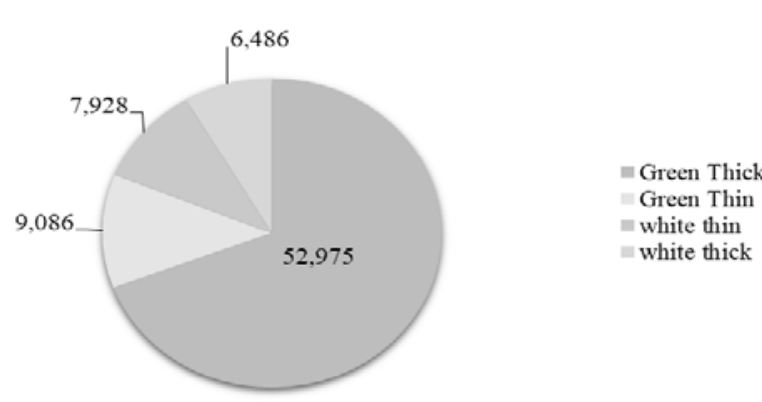

Figure 5: Monthly yarn requirement by type and total color for the week 
DOI: 10.14807/ijmp.v11i4.1111

Figure 5 shows that the wire that is most in need is the Thick type wire in green color, with approximately $212 \mathrm{~kg}$ per month, which is used by most products. Second comes the thin type yarn in green color with $36 \mathrm{~kg}$ and then the yarns: fine white and thick white, with approximately $32 \mathrm{~kg}$ and $26 \mathrm{~kg}$, respectively.

The total amount of each yarn and the weight of each spool were obtained, the amount of the monthly reel requirement for the production, as presented in Table 4.

Table 4: Monthly need for reels

\begin{tabular}{c|c|c|c}
\hline Type of wire & $\begin{array}{c}\text { Amount of } \\
\text { wire (Kg) }\end{array}$ & $\begin{array}{c}\text { Reel weight } \\
(\mathrm{Kg})\end{array}$ & $\begin{array}{c}\text { Amoung of } \\
\text { reel (Unit) }\end{array}$ \\
\hline Green thick & 52,975 & 3,64 & 59 \\
\hline Green thin & 9,086 & 4,26 & 9 \\
\hline White thin & 7,928 & 4,26 & 8 \\
\hline White thick & 6,486 & 3,64 & 8 \\
\hline
\end{tabular}

From Table 4 we observe a monthly requirement of 59 reels of the green thick type yarn, followed by 9 reels of the thin green yarn and 8 of the thin white and thick white yarn each.

After calculating the need for the main input, we proceeded to balance the weekly activities of the operators. In order to carry out this step, it was necessary to realign the strategy of receiving the suppliers, as well as the dates of delivery of products in process to third parties and to identify the new delimitations of the process.

The delimitations were:

- All Group B products that would be pumped by third parties must arrive at the company on Monday to follow the finishing process;

- All Group C products are due to arrive on Tuesday to follow the finishing process;

- All yarn Tuffing made by outsourced process should arrive on Wednesday;

- All cut Yarns must be delivered to third parties on Wednesday.

In this way, the delimitations of the system, the possession of the activity times and using the TOC concepts were defined, it was possible to elaborate the balance of activities, also respecting the limitations of each of the three operators, which are presented in Table 5.

Table 5: Available times for operators

\begin{tabular}{c|c|c|c}
\hline & Operator A & Operator B & Operator C \\
\hline Days of the week worked & 3 & 5 & 5 \\
\hline Hours worked per day & 8,8 & 8,8 & 8,8 \\
\hline
\end{tabular}


DOI: 10.14807/ijmp.v11i4.1111

\begin{tabular}{c|c|c|c} 
Minutes worked per day & 528 & 528 & 528 \\
\hline Setup (min) & 60 & 30 & 30 \\
\hline Total Time (min) & 468 & 498 & 498 \\
\hline
\end{tabular}

Operator A works 3 days a week, 8.8h each day, totaling 528 work minutes per day. Operators B and C work 5 days a week, totaling the same 528 minutes per day. For operator B and $\mathrm{C}$ was discounted 30 minutes of setup, however for the operator $\mathrm{A}$ was considered 60 minutes of setup, total time for heating the oven. Therefore, as total time available we obtained 468 minutes for operator A and 498 minutes for operators B and C. Besides that, it was considered as a tolerance factor of $20 \%$, knowing that an operator cannot work an entire period without interruptions, either by physical, physiological or for reasons beyond his control, so the established efficiency was 80\% under time of 468 and 498 minutes.

Given the mentioned information, the balance of activities for operator was carried out. A total working time of 404 minutes was obtained, which corresponds to an efficiency of $81 \%$, very close to the previously established efficiency of $80 \%$.

\subsubsection{Create Production Order}

With balanced production, it was possible to prepare the Production Order, which presents information such as: date of production, product to be produced and quantity to be produced.

The production order was elaborated based on the monthly sales target already defined, 1000 products in total, being divided according to demand forecast. It is important to highlight that the production orders were elaborated respecting the restrictions defined by the TOC, and considering the individuality of each operator, respecting their working hours and capacities.

An important change here is the fact that the BPP used by the company previously divided production only between domestic brooms and industrial brooms, not specifying which model of each product should be produced. The Production Order developed after this study identifies which model should be produced, offering greater assertiveness in forecasting demand.

\subsection{Control of Production}

\subsubsection{Determining the Security Stock}

The security stock will be of great importance to the company, since in addition to offering protection to variations in demand; it will also absorb the failures of its suppliers. In addition, with the right amount of input stocks, opportunities for improvements in layout may 
DOI: 10.14807/ijmp.v11i4.1111

arise, and before this work, the company made its purchases of inputs according to the suppliers' offer, causing high levels of inventories in the factory.

In order to determine the security stock of the main inputs: reels, strains and plaques, it was first established that the level of security stock should be sufficient to cover production in a period of one week. After that, the calculations of the quantities needed to be kept in stock were carried out.

In order to calculate the stock of plastic broom strain it was necessary to identify which plastic broom strain models each product used, since there are more than one size. Then, the required weekly quantity was calculated using the quantity of each type of product to be produced, obtaining the safety stock. It was obtained that for the safety stock it would be necessary to maintain 251 plastic broom strain, divided into 5 different types.

Finally, the security stock of plates was calculated, which are used only in industrial brooms to attach them to wooden cables. As well as the calculation of the strains, their quantity was obtained according to the quantity of product that uses this input. At the end of the security inventory, it was established that the following would be kept in the factory: 22 spools, distributed among the different types of yarn, as shown in Table 5, 251 strains, distributed among the 5 existing sizes and 280 iron rods for industrial production brooms.

\section{CONCLUSIONS}

Production Planning, Programming and Control has proven to be an efficient tool in the pursuit of production excellence. Increased productivity and assertiveness in demand forecasting, lower inventories and production costs and efficient use of resources are some of the results presented when this tool is used correctly.

The objective of this work was to propose a hybrid model of PPCP implementation in a small company, allowing its development step by step. However, the model was generic enough to serve as a guide and replicated in other small companies.

The model was constructed using the concepts of Lean Manufacturing, Push Production (MRP and MRP II) and Theory of Constraints in each of its three phases: planning, programming and control. By exploring the advantages of each of these concepts and adapting the reality of the company under study, it was possible to create an adaptable model that offered notable contributions to the company. 
DOI: 10.14807/ijmp.v11i4.1111

Among the model's main gains were the planning phase, which was knowledge of the productive capacity, identification of the processes that aggregate and do not add value to the consumer. In addition, identification of production bottlenecks, identifying the processes that should receive the most efforts in their optimization, and finally, a more assertive forecast of demand, which considered the different models of product existing in the company.

In the Production Scheduling phase with the production balancing and the concepts of the production pushed it was possible to establish a change in the relations with suppliers and third parties adapting them to the needs of the company, which later allowed the construction of the production orders offering the operators activities.

Finally, in the Production Control phase, the security stocks were defined within the concept of Lean Manufacturing, which preaches the maintenance of minimum inventories that can absorb any faults in the process or suppliers, enabling the company to significantly reduce costs. It is noteworthy that in this phase a spreadsheet was developed that offers the company better visual management and decision support, allowing the company to become more and more assertive in its processes through continuous improvement.

In general, the implementation of the Planning, Programming and Production Control tool brought the company a better management of its material and human resources, allowing its better prospection and advantage in the existing competitive market.

\section{REFERENCES}

ACS, Z. J.; MORCK, R.; SHAVER, J. M.; YEUNG, B. (1997) Small Business

Economics, v. 9, p. 7-20. doi: 10.1023/A:1007991428526

ALVES, R.; SANTOS, J. A. A.; SCHMIDT, C. A. P. (2014) Aplicação dos princípios da teoria das restrições e de técnicas de simulação na gestão da dinâmica operacional de um pequeno restaurante: um estudo de caso. Espacios, v. 35, n. 7, p. 21- 29.

AKMAL, A.; PODGORODNICHENKO, N.; GREATBANKS, R.; EVERETT, A. M. (2018). Bibliometric analysis of production planning and control (1990-2016). Production Planning and Control, v. 29, n. 4, p. 333-351.

ASSID, M.; GHARBI, A.; DHOUIB, K. (2015) Joint production and subcontracting planning of unreliable multi-facility multi-product production systems. Omega, n. 50, p. 54-69.

ASSOCIAÇÃO BRASILEIRA DA INDÚSTRIA DO PET (ABIPET) Panorama do Setor. Available in: http://www.abipet.org.br, access in: Junho/2019.

ASSOCIAÇÃO BRASILEIRA DA INDÚSTRIA DO PET (ABIPET) Indústria do Pet no Brasil: Mercado, Perspectivas e Reciclagem. Available in: http://www.abipet.org.br, access in: Junho/2019.

BECK, T.; DEMIRGUC-KUNT, A. (2006) Small and medium-size enterprises: Access to finance as a growth constraint. Journal of Banking \& Finance, v. 30, n. 11, p. 2931-2943. 
BERTOLINI, M.; ROMAGNOLI, G.; ZAMMORI, F. (2015) Simulation of two hybrid production planning and control systems: A comparative analysis. In: Industrial Engineering and Systems Management (IESM), International Conference on. IEEE, p. 388-397.

EASTERBROOK, S.; SINGER, J.; STOREY, M. A.; DAMIAN, D. (2008) Selecting Empirical Methods for Software Engineering Research. In: Shull F., Singer J., Sjøberg D.I.K. (eds) Guide to Advanced Empirical Software Engineering. Springer, London.

FERNANDES, F. C. F.; AZEKA, F.; BARRETO, M. C. M.; FILHO, M. G. (2007) Identificação dos principais autores em planejamento e controle da produção por meio de um survey mundial com pesquisadores da área. Gestão \& Produção, v. 14, n. 1, p. 83-95.

FERNANDES, F. C. F.; FILHO, M. G.; BONNEY, M. (2009) A proposal for integrating production control and quality control. Industrial Management \& Data Systems, v. 109, n. 5, p. 683-707.

FORSMAN, H.; RANTANEN, H. (2011) Small manufacturing and service enterprises as innovators: a comparison by size. European Journal of Innovation Management, v. 14, n. 1, p. 27-50. doi:10.1108/14601061111104689

GALDAMEZ, E. V. C. (2007) Proposta de um Sistema de Medição de Desempenho para Clusters Industriais de Pequenas e Médias Empresas. Tese de Doutorado. Universidade de São Paulo (Usp), São Carlos-SP.

GIAOUTZI, M.; NIJKAMP, P.; STOREY, D. J. (2016) Small and medium size neterprises and regional development. Routledge, London.

GUAN, X.; MA, S.; YIN, Z. (2015) The impact of hybrid push-pull contract in a decentralized assembly system. Omega, v. 50, p. 70-81.

GUNASEKARAN, A.; RAI, B. K.; GRIFFIN, M. (2011) Resilience and competitiveness of small and medium size enterprises: an empirical research. International Journal of Production Research, v. 49, n. 18, p. 5489-5509, doi: 10.1080/00207543.2011.563831

HSIEH, Y.; CHOU, Y. (2017) Modeling the impact of service innovation for small and medium enterprises: A system dynamics approach. Simulation Modelling Practice and Theory, v. 82, p. 84-102.

KORUGAN, A.; GUPTA, S. M. (2014) An adaptive CONWIP mechanism for hybrid production systems. The International Journal of Advanced Manufacturing Technology, v. 74, n. 5-8, p. 715-727.

KOTHARI, C. R. (2004) Research Methodology, methods and techniques. 3 ed. New Age International (P) Ltd.

KUAZAQUI, E. (2013) Brazilian micro-enterprises: an exploratory study on marketing strategies. China-USA Business Review, v. 12, n. 10.

KUMAR, R. (2011) Research Methodology, a step-by-step guide for beginners. 3 ed. SAGE Publications Ltd.

SALEEM, J. J.; MILITELLO, L. G.; RUSS, A. L.; WILCK, N. R. (2016) The need for better integration between applied research and operations to advance health information technology. Healthcare, v. 4, n. 2, p. 80-83.

SJOBERG, D.; DYBÅ, T.; JORGENSEN, M. (2007) The Future of Empirical Methods in Software Engineering Research. FoSE 2007: Future of Software Engineering, p. 358-378. 10.1109/FOSE.2007.30. 
WANG, C.; LIU, X. B. (2013). Integrated production planning and control: A multiobjective optimization model. Journal of Industrial Engineering and Management, v. 6, n. 4, p. 815-830.

ZAHRAEI, S. M.; CHEE-CHONG, T. (2017) Optimizing a supply network with production smoothing, freight expediting and safety stocks: An analysis of tactical trade-offs. European Journal of Operational Research, v. 262, n. 1, p. 75-88. 